\title{
Analysis and Tests on Weak-Form Efficiency of the EU Carbon Emission Trading Market
}

\author{
Xing Yang1,2, Hanfeng Liao ${ }^{*}$, Xiaoying Feng1, Xingcai Yao ${ }^{2}$ \\ ${ }^{1}$ School of Economics, Jinan University, Guangzhou, China \\ ${ }^{2}$ School of Economics, Guangzhou College of SCUT, Guangzhou, China \\ Email: *liaohanfeng000@163.com
}

How to cite this paper: Yang, X., Liao, H.F., Feng, X.Y. and Yao, X.C. (2018) Analysis and Tests on Weak-Form Efficiency of the EU Carbon Emission Trading Market. Low Carbon Economy, 9, 1-17. https://doi.org/10.4236/lce.2018.91001

Received: January 22, 2018

Accepted: March 4, 2018

Published: March 7, 2018

Copyright ( 92018 by authors and Scientific Research Publishing Inc. This work is licensed under the Creative Commons Attribution International License (CC BY 4.0).

http://creativecommons.org/licenses/by/4.0/

\begin{abstract}
This study separately applies Lo MacKinlay traditional variance ratio test, Wright non-parametric test, Chow Denning multiple variance ratio test and Joint Wright multiple variance ratio test to analyze and test the features of the EU carbon emission market and the results show that: in the 12-year development of the EU carbon emission trading, only the rate of return in the second stage follows the Martingale Process, showing a weak-form efficient market, while the first and third stages fail to possess features of an efficient market.
\end{abstract}

\section{Keywords}

Carbon Emission Market, Weak-Form Efficiency, Variance Ratio Tests

\section{Introduction}

The Efficient Markets Hypothesis (EMH) is the basis of modern finance theory. Eugene Fama [1] defined an Efficient Market as: when the market price can at any time fully reflect all available information, investors will not be able to obtain excess profits from their investment strategies and the price of each bond will always equal to the value of investment, and as such, the capital market is efficient. In order to make the "fully reflect" specific and to test market efficiency empirically, Fama divided efficient markets into three categories: weak-form efficient market, semi-strong-form efficient market and strong-form efficient market. In a weak-form efficient market, historical information can be fully reflected by the market price; in a semi-strong-form efficient market, the price can fully reflect historical information and public information; while in a strong-form efficient market, the price can adequately reflect historical information, public information and internal information. Obviously, a strong-form ef- 
ficient market does not exist in reality and a strong-form efficient market exists only when the public information has no "noise". Hence, if a capital market is efficient, it will be more likely to show features in accordance with a weak-form efficient market.

Carbon emission trading market is a new type of capital market. The original intention of implementing such a market was to protect the environment of human survival and development and to make rational use of resources. The European Union Emissions Trading System (EU ETS) is currently the largest and the most standard one, not only for spot trading of carbon emissions, but also for derivatives, such as futures and options. The current European carbon emissions trading market has developed rapidly, so, what's the market efficiency, does it have the feature of market efficiency? This is a research with theoretical and practical significance, which has a certain guiding significance for further improving of the global carbon emission trading system. At present, there exists a large number of trading costs, information asymmetry as well as a lack of rational investors, and its market price mainly reflects the historical information. In view of this, it could be assumed as a weak-form efficient market. However, it should be tested that whether or not the features of actual market are in accordance with the hypothesis, which is also the original intention of this study.

Charles et al. [2] study the effectiveness of the European carbon emission trading market from the cost-of-carry hypothesis. The three main European markets (BlueNext, EEX and ECX) are analyzed during Phase II, covering the period from March 13, 2009 to January, 17, 2012. The result shows that the carbon emission market is not yet effective, and there may be a chance of arbitrage. Daskalakis [3] examine in the period 2008-2011 the efficiency of four carbon dioxide $\left(\mathrm{CO}_{2}\right)$ emission allowance futures traded in the Intercontinental Exchange (ICE). The results from 2010 onwards are consistent with weak market efficiency. Roselyne [4] use the cost-of-carry model to investigate the extent of market efficiency in the EU futures market for carbon dioxide allowances over the period of June 2005 to December 2007 and find some evidence of improvement in market efficiency over the period. Montagnoli [5] believed, as usually is the case in emerging and non-competitive markets such as the EU ETS, trading often not occurs on a frequent basis. This has adverse implications for both the gains from permit trade as well as biases the EMH tests. Variance ratio tests are employed to adjust for the thin trading effect. The results indicate that Phase I-the trial and learning period-was inefficient, whereas the first period under Phase II shows signs of restoring market efficiency. Daskalakis and Markellos [6] examined the efficiency of the European carbon market during Phase I of its operation (2005-2007). The authors provided evidence that the EU ETS was far from efficient, a finding they attributed to its short history.

From the current research, international research on the effectiveness of the market for European carbon emissions is less, and research emphasis is largely based on carbon emission rights from the futures market, spot market effective- 
ness research almost no, this study will enrich the research of this field. By understanding the market efficiency, so as to reflect the advantages and disadvantages of the current international carbon trading market system, and provides some references for the mechanism design of the international carbon trading market.

The study includes the following three parts: first, a theoretical analysis on the effectiveness of EU ETS was made; then, the weak-form effectiveness of EU ETS separately tested by Lo MacKinlay traditional variance ratio test, Wright non-parametric test, Chow Denning multiple variance ratio test and Joint Wright multiple variance ratio test; finally, the results were compared, analyzed and interpreted.

\section{Analysis on Weak-Form Effectiveness of the EU ETS}

The EU carbon emission trading system was officially operated on January 1, 2005. After a 12-year development, it is now holding a relatively well-established legal system and a trading mechanism. According to the EMH theory, an efficient financial market must be in accordance with three basic hypotheses: first, no trading cost, namely a market without friction; second, no information cost, meaning that all market participants have unconditional access to all information; third, rational investors, which means all participants agree with the information contained in the current price and the forecast on future price. When all the three hypotheses are met, the market is considered to be efficient. Obviously, this is an ideal condition. The efficiency of the EU ETS can be analyzed as follows.

\subsection{Analysis on Trading Cost}

The EU ETS has led to a large number of trading cost since its establishment. Trading cost of EU ETS can be divided into two categories: one is the management cost on initial allocation of quotas, while the other is the cost on trading these quotas. On the one hand, to maintain the running of the carbon trading system, the authorities will charge enterprises a certain amount of fees when allocating quotas, which forms the management cost including related fees in the quota application process, service charge of the registration system, cost on the Monitoring Verification Reporting System (MVR), as well as other additional fees like related costs generated from making carbon balance sheets; on the other hand, to better use the carbon trading market to achieve emission reduction targets, enterprises need to perform activities such as predicting emission, identifying and assessing various emission reduction strategies, forecasting changes of quota prices, analyzing the sensitivity, seeking for trading counterparties, executing trading and managing risks, all of whose expenditures will generate the trading cost. Among all these costs, some only occur at the beginning of the trade, which are one-time costs like the application fee; some will occur every year like the monitoring verification reporting cost; and the others are based on 
the trading volume, including cost on seeking counterparties.

\subsection{Analysis on Information Cost}

Similar to the common stock market, there is a great deal of information asymmetry in the carbon trading market, which leads to a relatively high cost of information. The information asymmetry in the carbon trading market is mainly reflected between the participants and the government decision makers, as well as among the participants.

Asymmetry between the participants and the government decision-makers is reflected in two phases. The first phase is setting the total amount of quotas. Under the control of total amount and the trading system, government decision makers need to determine the total amount of quotas to be allocated according to the total amount of emission reduction within a certain period of time. The total amount of emission reduction depends on the total emission in base period and the emission reduction rate which should be estimated according to the overall emission reduction capacity of an enterprise, a piece of private information that is difficult for the decision makers to obtain. Moreover, given that being set at the beginning of the period and remaining unchanged in the compliance period, the total emission reduction will not be able to be adjusted according to corporate emission reduction capacity and thus characterized in "Supply Rigidity", causing a difficulty for the quota price to reflect all information. The second phase is allocating quotas. Under the free allocating system, decision makers need to determine the allocation according to the corporate expecting reduction ratio or the input-output. However, as management costs and capacities are both private to enterprises, a problem of "adverse selection" may be caused, which means that enterprises with low capacity, high emission, high management cost and low emission reduction capacity will get more quotas. As a result, resource allocation and market prices will be distorted and emission reduction effects will be lowered. Under the auction system, information asymmetry is more pervasive. Enterprises are not able to determine the current quota prices according to the overall emission of the future market and thus experiencing difficulties in making an accurate judgment on the initial quota prices.

The asymmetry of information among participants is mainly the information asymmetry during trading, which will lead to price distortions. Consequently, market prices will be distorted and deviating from the equilibrium price derived under complete information.

\subsection{Analysis on Rational Investors}

In the current EU ETS, policy issues are leading to expectation bias, the vacancy of market system increases the difficulty of investment and market subjects are in a relatively small amount. Therefore, rational investors are difficult to emerge in the market.

Policy issues are leading to expectation bias. The carbon trading market is 
based on a series of policies and thus being easily affected by changes and unreasonable arrangements of the policy. Since the establishment of the EU ETS, the carbon trading market has witnessed several major changes of policies, causing abnormal fluctuations of carbon quota prices. For instance, in the first half of 2013, Industry Committee of the European Parliament rejected the EU Commission's "quantity-limited and price-maintained" market-boost plan by a vote of 334 to 315, proposing a delayed auction on carbon quotas to the European Council to freeze a 0.9 billion tons of carbon quota, so as to improve the carbon market price. This change of policy triggered a slump of carbon quota price from 30 Euros per ton to 2.72 Euros per ton, a new lowest record in history. Deeney [7] found that specific types of EP decisions lead to reduced carbon prices and increased volatility. Unstable policies have made it difficult for investors to reasonably expect the price, which eventually leads to irrational investment.

The vacancy of market system increases the difficulty of investment. Perthuis [8] believe that the system has been undermined variously by the weakness of its regulation, an undesirable overlap with other public policies and the far-reaching economic and financial crisis that caused the market price of allowances to plunge. In 2005, when the EU launched the EU ETS, many systems were not yet mature. The total carbon quota of the testing period had not been finalized until mid-2005. Member states have not yet got ready for the final allocation plan and there is still a problem of quota rigidity to be solved between total amount control and the trading system. At the end of the compliance period, problems of both surplus and shortage of carbon quotas will cause unexpected fall or rise of prices, adding more difficulties to investors' decision-making.

Market subjects are in a relatively small amount, making it difficult to ensure an overall rationality of the market. First, the participants are mainly from large emission enterprises of important industries, emitting about $50 \%$ of the total $\mathrm{EU}$ greenhouse gas. While the other $50 \%$ of the emission is not due to departments or enterprises, information received by investors is limited and the price is not able to reflect all the information; secondly, different from the general stock market, participants of the EU ETS carbon quota trading market are from only the supply and demand sides. A lack of third-party investors like a large number of arbitragers reflects an imperfect arbitrage mechanism, which impedes the price to timely recover to equilibrium.

From the analysis above, we can conclude that the current EU ETS has a large amount of trading cost, asymmetric information and irrational investors, which means that EU ETS is a non-efficient market. However, seen from the market price changes of current EU ETS, although the price of carbon quota fails to fully reflect all the internal and public information, it has already reflected the historical information of the price. Accordingly, we believe the EU carbon trading market has been characterized in weak-form efficiency, which yet needs to be tested empirically. 


\section{Empirical Test on Weak-Form Efficiency of the EU ETS}

We have applied the variance ratio test (VR Test) to determine the efficiency of the market, and the main idea is: if the price follows a martingale process, then variance of the $K$ period should be $K$ times that of the first period. The VR test does not require a normal distribution and it allows the existence of heteroscedasticity. The basic principle testing the weak-form efficient market by martingale process of the price is: if price or return follows a certain martingale process, then the market is weak-form efficient.

Random walk model is the most effective among the three martingale models, and its mathematical expression is:

$$
P_{t}=E+P_{t-1}+\varepsilon_{t}
$$

Among them, $P_{t}$ represents price or its logarithm, $E$ is expected value of price (excess profit), while $\varepsilon_{t}$ stands for error.

The random walk models can be divided into: $R W_{1}, R W_{2}$ and $R W_{3}$. When $\varepsilon_{t} \sim N\left(0, \sigma^{2}\right)$, which means the distribution is independent and identical with an average of 0 and a variance of $\sigma^{2}$, then $R W_{1}$; when the hypothesis of identical distribution is relaxed and the distribution is only independent, we can conclude that $R W_{2}$; if we continue relaxing the independent conditions, namely a non-independent and identical distribution, then $R W_{3} \cdot R W_{3}$ is the poorest random walk model but has been widely used because it is the most realistic one. When $E=0$, the market is efficient. If $E \neq 0$, it is considered that there are information costs, trading costs and irrational investors, then the market may be weak-form efficient or inefficient. Therefore, tests on $R W_{3}$ could be seen as tests on efficient market. Variance ratio tests are usually applied to test $R W_{3}$.

The carbon emission rights market has experienced three stages. The first phase (2005-2007) of the EU ETS was a pilot phase to test the system. The Member States had the freedom to decide on how many EUAs to allocate in total as well as to each installation in their territory by preparing national allocation plans (NAPs). Almost all EUAs were allocated for free and were based on historic emissions called grandfathering. During the second phase (2008-2012), 10\% of the allowances could be auctioned by the Member States instead of free allocation. During the third phase (2013-2020), the main allocation method was modified from grandfathering to auctioning as a principle and some remaining free allocation based on benchmarks. In 2013, allowances for more than $40 \%$ of all verified emissions were auctioned. Due to the system changes in different stages, we will discuss the effectiveness of the market in different stages.

We have separately applied Lo MacKinlay traditional variance ratio test, Wright non-parametric test, Chow Denning multiple variance ratio test and Joint Wright multiple variance ratio test to test the weak-form efficiency of the market. The market return in the three stages are respectively represented by: $r_{1}, r_{2}$ and $r_{3}$.

\subsection{Data Sources and Descriptive Statistical Characteristics}

Data in this paper are the EUA spot prices from the European Climate Exchange 
(ECX). Sample data have covered from June 24, 2005 to January 5, 2017, a period of which is divided into three stages. Samples for the first stage are EUA (2005-2007) from June 24, 2005 to April 25, 2008, a total of 708 observations; for the second stage are EUA (2008-2012) from February 26, 2008 to April 30, 2013, a total of 1286 observations; for the third stage are EUA (2013-2020) from December 7, 2012 to March 31, 2017, a total of 1159 observations. Hence, the total sample consists of 3153 observations. Since the carbon quotas issued at each stage will still be traded for a period of time after the end of that stage, there will be an overlapping time among the samples. The price data are from the Bloomberg database.

Table 1 shows the statistical characteristics of daily return in the EUA spot market in three stages of the EU-ETS, while Figure 1 presents the distributions of daily return in the EUA market in three stages of the EU-ETS. $r_{1}, r_{2}$ and $r_{3}$ are respectively the daily return in three stages. Among them, the QQ diagram, a quantile-quantile figure, is used to make a comparison between two distributions, namely the daily return distribution and the normal distribution, so as to find out whether they are the same.

Analyzed from the skewness, the daily return distributions of $S<0$ in the three stages are all left-skewed and with asymmetry. Analyzed from the kurtosis, compared to the normal distributions, the daily return distributions of $K>3$, in the three stages show a leptokurtosis and fat-tail, demonstrating characteristics of general financial data. The JB statistics are statistically significant, which means that the daily return distribution fails to follow the normal distribution.

In the daily return distribution figures, we can see substantial fluctuations of the daily return at the end of the first stage. The daily return in the second stage is relatively stable except some abnormal fluctuations at the end of this stage. In the third stage, the daily return fluctuates greatly with abnormal waves at the beginning of this stage.

Table 1. 2005-2017 Statistical characteristics of daily return in the EUA spot market in three stages of the EU-ETS.

\begin{tabular}{cccc}
\hline & $r_{1}$ & $r_{2}$ & $r_{3}$ \\
\hline Observation & 707 & 1285 & 1158 \\
Average & -0.0110 & -0.0015 & -0.0002 \\
Median & 0.0000 & -0.0007 & 0.0000 \\
Maximum value & 0.6931 & 0.2399 & 0.2399 \\
Minimum value & -0.6931 & -0.4314 & -0.4314 \\
Standard deviation & 0.0960 & 0.0341 & 0.0373 \\
Skewness $(S)$ & -0.6696 & -1.1627 & -1.1319 \\
Kurtosis $(K)$ & 18.8756 & 26.8581 & 21.9755 \\
JB Statistics & 7477.2410 & $30,765.8600$ & $17,620.56$ \\
Probability & 0.0000 & 0.0000 & 0.0000 \\
\hline
\end{tabular}



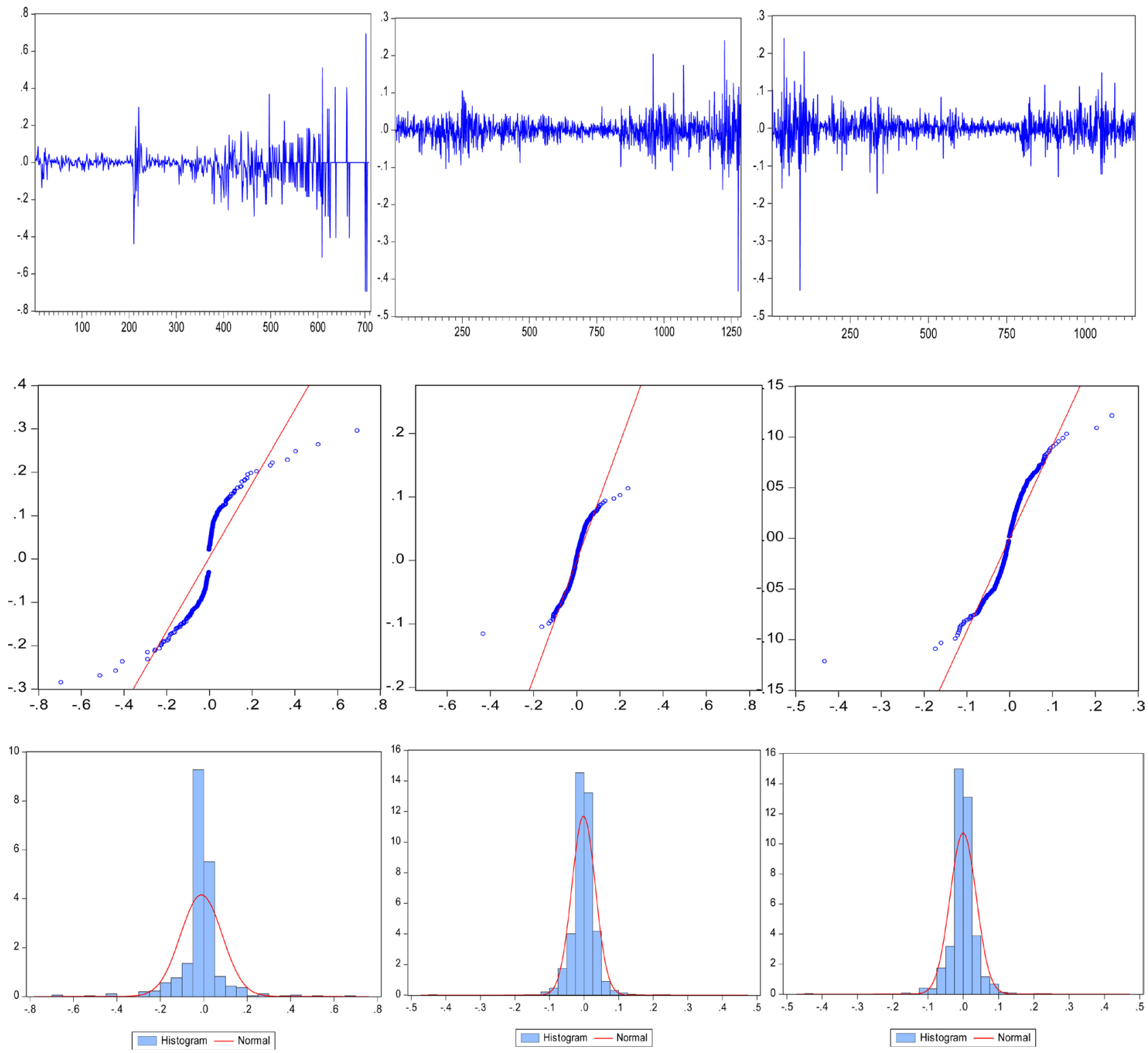

Figure 1. 2005-2016 Daily return distribution diagrams, QQ diagrams and Density maps of the EUA market in the three stages of the EU-ETS

In the QQ diagrams, goodness of fit between the daily return and the normal distribution is relatively poor in the first stage, while an opposite condition can be found between the second and the third stages yet differences from the normal distribution still exist since there are points of inflection.

Seen from the density maps, distributions of the three stages are all characterized in leptokurtosis and fat-tail.

Since all the three daily return distributions are not normal distributions, it is not appropriate to use the unit root test and the serial correlation test. Therefore, we choose the variance ratio test to test the weak-form efficiency of the EU-ETS.

Under the variance ratio test: when the original hypothesis is valid to all and the EUA daily return follows a martingale process, then the market is weak-form 
efficient; when the alternative hypothesis is valid in some conditions and the EUA daily return does not follow a martingale process, then the market is non-efficient.

According to Kim and Shamsuddin [9], the variance ratio test is suitable for short holding periods, so we choose the daily return holding period $K$ as $(2,5,10$, $20,40)$. Since the daily trading volumes in the EU-ETS are in a relatively small volume, an insufficient liquidity will affect the test results. For such markets, there are two methods for adjustment. One is to use mid and low frequency data, and the other is to use the moving average process to eliminate the impact. In this paper, we adjust the daily return of the EUA by estimating the AR (1) process.

\subsection{Analysis on the Results of Variance Ratio Test}

In this paper, spot prices of the EUA are converted into spot daily returns of the EUA, among which $r_{t}=\log \left(p_{t} / p_{t-1}\right)$ is the spot price of the EUA at time t. After conversion, samples in three stages are respectively 707, 1285 and $1158 \mathrm{ob}-$ servations, a total of 3190 observations. Test results of the four methods are as follows:

\subsubsection{Lo MacKinlay Traditional Variance Ratio Test}

Lo and MacKinlay [10] believed that variance of the martingale process is a linear function with interval samples, which means that if the time series follows the martingale process, the variance will increase linearly with time and the variance of period $K$ is $K$ times that of the first period. If the time series or its first order difference is given, then the variance ratio in period $K$ is:

$$
\begin{aligned}
V(k) & =\frac{\operatorname{var}\left(x_{t}+x_{t+1}+\cdots+x_{t-k+1}\right) / k}{\operatorname{var}\left(x_{t}\right)} \\
& =\frac{\operatorname{var}\left(y_{t}-y_{t-k}\right) / k}{\operatorname{var}\left(y_{t}-y_{t-1}\right)} \\
& =1+2 \sum_{i=1}^{k-1} \frac{(k-i)}{k} \rho_{i}
\end{aligned}
$$

In this equation, $\rho_{i}$ is the $\mathrm{i}(\mathrm{th})$ order lagged autocorrelation coefficient of $\left\{x_{i}\right\}$ and $V(k)$ is a linear combination of the first order autocorrelation coefficient and the linearly decreasing weight. When the time series is non-auto correlated, $\operatorname{var}\left(x_{t}+\cdots+x_{t-k+1}\right)=k \cdot \operatorname{var}\left(x_{t}\right)$. Therefore, we can conclude that the variance ratio test is a special case of the serial correlation test. The following statistical estimation can be established:

$$
V R(k)=\frac{\hat{\sigma}^{2}(k)}{\hat{\sigma}^{2}(1)}
$$

In this equation, $\hat{\sigma}^{2}(1)$ is the unbiased estimation of the variance in period 1 , and $\hat{\sigma}^{2}(k)$ is the unbiased estimation of period $K$.

We use two test methods respectively under homoscedasticity and heterosce- 
dasticity. First, we assume that when $T$ tends to infinity, $k$ will not change. Then we can get the gradual distribution of $V R(x ; k)$.

Under homoscedasticity, the null hypothesis is $V(k)=1$, so we can establish the statistics as:

$$
M_{1}(k)=\frac{V R(x ; k)-1}{\Phi(k)^{1 / 2}}
$$

In this equation, $\Phi(k)$ is the gradual variance:

$$
\Phi(k)=\frac{2(2 k-1) \cdot(k-1)}{3 k T}
$$

Under heteroscedasticity, the statistic is:

$$
M_{2}(k)=\frac{V R(x ; k)-1}{\Phi^{*}(k)^{1 / 2}}
$$

In this equation,

$$
\begin{gathered}
\Phi^{*}(k)=\sum_{j=1}^{k-1}\left[\frac{2(k-j)}{k}\right]^{2} \delta(j) \\
\delta(j)=\left\{\sum_{t=j+1}^{T}\left(x_{t}-\hat{\mu}\right)^{2}\left(x_{t-j}-\hat{\mu}\right)^{2}\right\} \div\left\{\left[\sum_{t=1}^{T}\left(x_{t}-\hat{\mu}\right)^{2}\right]^{2}\right\}
\end{gathered}
$$

$M_{1}(k)$ and $M_{2}(k)$ follow the gradual standard normal distribution.

If the time series follows the martingale process, then for all $k$, expected value of $\operatorname{VR}(x ; k)$ should equal to 1 . If the time series is positive (negative) correlated, then $V R(x ; k)$ should be greater than (less than) 1 . When $\mathrm{k}$ is relatively large and $\operatorname{VR}(x ; k)$ is significantly lower (higher) than 1 , then the time series has a property of (non) mean reversion.

Results of Lo MacKinlay Traditional Variance Ratio Test are shown in Table 2.

The results show that before adjustment of data, when there is heteroscedasticity, values of $r_{1}, r_{2}$ and $r_{3}$ cannot reject the original hypothesis, whereas when there is no homoscedasticity, the value of $M_{1}$ cannot reject the original hypothesis, which means that the daily return in the three stages of the EUA all follow the martingale process. And same results are obtained after data adjustment.

However, there are two problems in traditional variance ratio test. The first problem is that given this test is based on gradual approximate evaluation, a scale distortion of finite sample will occur. The other problem is related to the value of $K$. If the null hypothesis of time series following a mean reversion is to be accepted, then the null hypothesis of all $\mathrm{k}$ is not to be rejected, which leads to a problem of joint inspection to test whether the null hypothesis is valid to all $k$. In addition, another problem is that there is no optimal choice of $k$, leading to arbitrary selection of $k$.

\subsubsection{Wright Non-Parametric Test}

Wright non-parametric test is a correction to the problem of scale distortion in 
Table 2. Results of Lo MacKinlay traditional variance ratio test.

\begin{tabular}{|c|c|c|c|c|c|c|c|}
\hline \multirow{2}{*}{ Return } & \multirow{2}{*}{$k$} & \multicolumn{3}{|c|}{ Unadjusted } & \multicolumn{3}{|c|}{ Adjusted } \\
\hline & & $V R$ & $M_{1}$ & $M_{2}$ & $V R$ & $M_{1}$ & $M_{2}$ \\
\hline \multirow[t]{5}{*}{$r_{1}$} & 2 & 0.8581 & $-3.7721^{\star * \star}$ & -1.4101 & 1.0249 & 0.7435 & 0.3947 \\
\hline & 5 & 0.7497 & $-3.0381^{\star * *}$ & -1.2335 & 0.8257 & $-2.3784^{\star *}$ & -1.2819 \\
\hline & 10 & 0.6930 & $-2.4179^{* *}$ & -1.1485 & 0.8663 & -1.1836 & -0.6698 \\
\hline & 20 & 0.6470 & -1.8887 & -1.0845 & 0.7488 & -1.5112 & -0.9041 \\
\hline & 40 & 0.7214 & -1.0336 & -0.7015 & 0.6731 & -1.3642 & -0.8420 \\
\hline \multirow[t]{5}{*}{$r_{2}$} & 2 & 1.0537 & 1.9258 & 1.0292 & 1.0564 & $2.0214^{\star *}$ & 1.0790 \\
\hline & 5 & 0.9315 & -1.1201 & -0.6121 & 0.9339 & -1.0816 & -0.5901 \\
\hline & 10 & 0.9523 & -0.5065 & -0.2904 & 0.9548 & -0.4797 & -0.2746 \\
\hline & 20 & 0.8044 & -1.4109 & -0.8728 & 0.8003 & -1.4403 & -0.8930 \\
\hline & 40 & 0.7047 & -1.4773 & -0.9800 & 0.7054 & -1.4739 & -0.9811 \\
\hline \multirow[t]{5}{*}{$r_{3}$} & 2 & 1.0247 & 0.7384 & 0.3921 & 1.0249 & 0.7435 & 0.3947 \\
\hline & 5 & 0.8256 & $-2.3801^{\star *}$ & -1.2831 & 0.8257 & $-2.3784^{\star *}$ & -1.2819 \\
\hline & 10 & 0.8662 & -1.1850 & -0.6707 & 0.8663 & -1.1836 & -0.6698 \\
\hline & 20 & 0.7488 & -1.5113 & -0.9044 & 0.7488 & -1.5112 & -0.9041 \\
\hline & 40 & 0.6729 & -1.3646 & -0.8424 & 0.6731 & -1.3642 & -0.8420 \\
\hline
\end{tabular}

Note: $M_{1}$ is the statistic under homoscedasticity and $M_{2}$ is the statistic under heteroscedasticity, both of which are subject to the gradual normal distribution whose mean value is 0 and standard deviation is 1 . The critical values are respectively 2.58 and 1.96 under significant levels of $1 \%$ and $5 \% .{ }^{* * *}$ and ${ }^{* *}$ respectively shows the significance under significant levels of $1 \%$ and $5 \%$.

traditional variance ratio test. To solve the first problem, Wright [11] put forward the Rank and Sign based non-parametric test. Under non-normal and non-stable data, results of this test are better. When the sample size is relatively small, the rank test and the sign test will have accurate sample distributions, which do not need to follow the gradual distribution.

When the first order difference variance is given, $r(x)$ is set as the rank of $\left(x_{1}, \cdots, x_{T}\right)$ and the null hypothesis follows a martingale process, then we can define the sum of statistics of the rank test as:

$$
\begin{aligned}
& R_{1}(k)=\left(\frac{(T k)^{-1} \sum_{t=k}^{T}\left(r_{1, t}+\cdots+r_{1, t-k+1}\right)^{2}}{T^{-1} \sum_{t=k}^{T} r_{1, t}^{2}}-1\right) \times \Phi(k)^{-1 / 2} \\
& R_{2}(k)=\left(\frac{(T k)^{-1} \sum_{t=k}^{T}\left(r_{2, t}+\cdots+r_{2, t-k+1}\right)^{2}}{T^{-1} \sum_{t=k}^{T} r_{1, t}^{2}}-1\right) \times \Phi(k)^{-1 / 2}
\end{aligned}
$$

In these equations:

$$
\begin{gathered}
r_{1, t}=\frac{r\left(x_{t}\right)-(T+1) / 2}{\sqrt{(T-1) \cdot(T+1) / 12}} \\
r_{2, t}=\Phi^{-1} \frac{r(x)}{T+1}
\end{gathered}
$$




$$
\Phi(k)=\frac{2(2 k-1) \cdot(k-1)}{3 k T}
$$

Sum of statistics of the sign test is:

$$
\begin{gathered}
S_{1}(k)=\left(\frac{(T k)^{-1} \sum_{t=k}^{T}\left(s_{t}+\cdots+s_{t-k+1}\right)^{2}}{T^{-1} \sum_{t=k}^{T} s_{t}^{2}}-1\right) \times \Phi(k)^{-1 / 2} \\
S_{2}(k)=\left(\frac{(T k)^{-1} \sum_{t=k}^{T}\left(s_{t}(\bar{\mu})+\cdots+s_{t-k+1}(\bar{\mu})\right)^{2}}{T^{-1} \sum_{t=k}^{T} s_{t}(\bar{\mu})^{2}}-1\right) \times \Phi(k)^{-1 / 2}
\end{gathered}
$$

In these equations:

$$
\begin{gathered}
s_{t}=2 u\left(x_{t}, 0\right) \\
s_{t}(\bar{\mu})=2 u\left(x_{t}, \mu\right) \\
u\left(x_{t}, q\right)= \begin{cases}0.5 & \text { if } x_{t}>q \\
-0.5 & \text { otherwise }\end{cases}
\end{gathered}
$$

According to Wright's empirical study, statistical efficiency of $S_{2}(k)$ is very

\begin{tabular}{|c|c|c|c|c|c|c|c|}
\hline \multirow{2}{*}{ Return } & \multirow{2}{*}{$k$} & \multicolumn{3}{|c|}{ Unadjusted } & \multicolumn{3}{|c|}{ Adjusted } \\
\hline & & $R_{1}$ & $R_{2}$ & $S_{1}$ & $R_{1}$ & $R_{2}$ & $S_{1}$ \\
\hline \multirow[t]{5}{*}{$R_{1}$} & 2 & $2.9285^{\star * *}$ & 1.2967 & $7.9355^{* * *}$ & -0.8568 & -0.5695 & $10.9031^{* * *}$ \\
\hline & 5 & $3.0588^{\star * *}$ & 1.5093 & $10.8215^{* * *}$ & $-2.0801^{\star * *}$ & $-2.4272^{\star * *}$ & $18.9903^{* * *}$ \\
\hline & 10 & $2.8923^{\star * *}$ & 1.4217 & $13.6183^{* * *}$ & -1.0147 & -1.2416 & $27.9099^{* * *}$ \\
\hline & 20 & $2.2072^{\star * *}$ & 0.9177 & $17.4548^{* * *}$ & -0.0796 & -0.5538 & $39.4995^{\star * *}$ \\
\hline & 40 & $2.6863^{* * *}$ & 1.4151 & $22.3752^{* * *}$ & 0.6349 & -0.0559 & $54.6185^{* * *}$ \\
\hline \multirow[t]{5}{*}{$r_{2}$} & 2 & 1.3624 & 1.4781 & 1.1438 & 1.4346 & $1.5741^{\star *}$ & $19.7786^{* * *}$ \\
\hline & 5 & -0.6458 & -0.8443 & 0.2852 & -0.6161 & -0.8040 & $35.7133^{* * *}$ \\
\hline & 10 & -0.1693 & -0.2891 & 0.8741 & -0.1508 & -0.2643 & $52.3609^{\star * *}$ \\
\hline & 20 & 0.2315 & -0.1834 & 1.3808 & 0.2501 & -0.1626 & $75.0433^{* * *}$ \\
\hline & 40 & 0.2933 & -0.1960 & $1.7335^{\star *}$ & 0.3125 & -0.1738 & $106.1170^{\star * *}$ \\
\hline \multirow[t]{5}{*}{$r_{3}$} & 2 & -0.8632 & -0.5722 & $-1.5385^{\star *}$ & -0.8568 & -0.5695 & $10.9031^{* * *}$ \\
\hline & 5 & $-2.0731^{\star *}$ & $-2.4213^{\star * *}$ & $-1.7464^{\star *}$ & $-2.0801^{\star *}$ & $-2.4272^{\star * *}$ & $18.9903^{* * *}$ \\
\hline & 10 & -1.0082 & -1.2349 & -0.9351 & -1.0147 & -1.2416 & $27.9099^{* * *}$ \\
\hline & 20 & -0.0733 & -0.5488 & -0.0727 & -0.0796 & -0.5538 & $39.4995^{* * *}$ \\
\hline & 40 & 0.6304 & -0.0594 & 1.4076 & 0.6349 & -0.0559 & $54.6185^{\star * *}$ \\
\hline
\end{tabular}
poor. As a result, $S_{2}(k)$ is no longer used in practical applications. Therefore, we do not take the $S_{2}(k)$ test into consideration.

By simulating the exact distribution of the sample, we can get the values of $R_{1}(k), R_{2}(k)$ and $S_{1}(k)$ as shown in Table 3:

Table 3. Results of wright non-parametric test.

Note: The critical values of the Wright test are shown in attached table one. ${ }^{* * *}$ and ${ }^{* *}$ respectively shows the significance under significant levels of $0.5 \%$ and $5 \%$. 
From the test results in Table 3 we can see that, different from the Lo MacKinlay traditional variance ratio test, $r_{1}, r_{2}$ and $r_{3}$ in the adjusted $S_{1}$ are statistically significant, and regardless of being unadjusted or adjusted, almost all the rank and sign statistics of $r_{1}$ are statistically significant, thus rejecting the original hypothesis of the martingale process; the unadjusted $r_{2}$ are statistically significant when $k=40$ and the adjusted $r_{2}$ are significant when $k=2$, while adjusted $r_{3}$ is significant in statistics when $k=5$. Therefore, under the Wright non-parametric variance ratio test, we can draw a more reliable conclusion in this paper, which is that the daily return in the first stage of the EUA does not follow the martingale process while its counterparts in the second and third stages follow the martingale process.

\subsubsection{Chow Denning Multiple Variance Ratio Test}

To solve the second problem related to the value of $k$, Chow and Denning [12] put forward the multiple variance ratio test (Multiple VR Test), which performs better when the sample size is relatively small and there is no scale distortion. Hypothesis of the multiple variance ratio test is:

H0: valid to all $i, i=1, \cdots, m, V\left(k_{i}\right)=1$, the corresponding time series follows the martingale-difference sequence, and is random walk;

$\mathrm{H} 1$ : valid to some $i, V\left(k_{i}\right) \neq 1$. Time series do not follow a martingale difference sequence.

If we accept the original hypothesis which means that the return sequence of the EU carbon market price is in line with the martingale-difference sequence, the EU market can be seen as a weak-form efficient market.

Statistics given by Chow and Denning (1993) are:

$$
\begin{gathered}
C D_{1}=\sqrt{T} \max _{1 \leq i \leq m}\left|M_{1}\left(k_{i}\right)\right| \\
C D_{2}=\sqrt{T} \max _{1 \leq i \leq m}\left|M_{2}\left(k_{i}\right)\right|
\end{gathered}
$$

In these equations, $M_{1}\left(k_{i}\right)$ and $M_{2}\left(k_{i}\right)$ are statistics of the Lo MacKinlay variance ratio test.

These statistics follow the SMM with degrees of freedom as $m$ and $T$, and $m$ is the number of values of $k$. In order to control the scale of the multiple variance ratio test, and because the finite distribution of the statistics is relatively complex, Chow and Denning used the Sidak probability inequality to give the upper limit of the critical value of SMM.

If the value of $\mathrm{CD}$ is greater than $\left[1-\left(\alpha^{*} / 2\right)\right] \%$ in standard normal distribution, and among which $\alpha^{*}=1-(1-a) 1 / m$, then the original hypothesis is rejected.

Results of the Chow Denning test are shown in Table 4: regardless of being before or after the adjustment, when there is heteroscedasticity, values of $r_{1}, r_{2}$ and $r_{3}$ are not statistically significant; while under homoscedasticity, the value of $r_{2}$ is not statistically significant as well, and the result is similar to the traditional variance ratio, meaning that the EUA daily returns in the three stages are 
all martingale processes.

\subsubsection{Joint Wright Multiple Variance Ratio Test}

Joint Wright multiple variance ratio test has integrated Wright non-parameter test and Chow Denning multiple variance ratio test, which corrects the two defects of traditional variance ratio test at the same time. It not only overcomes the problem of scale distortion among small-size samples, but also solves the problem of selecting $k$, thus making a better test effect.

Sum of statistics of the rank test and the sign test of multiple variance ratio is as follows:

$$
\begin{aligned}
& J R_{1}=\max _{1 \leq i \leq m}\left|R_{1}\left(k_{i}\right)\right| \\
& J R_{2}=\max _{1 \leq i \leq m}\left|R_{2}\left(k_{i}\right)\right| \\
& J S_{1}=\max _{1 \leq i \leq m}\left|S_{1}\left(k_{i}\right)\right| \\
& J S_{2}=\max _{1 \leq i \leq m}\left|S_{2}\left(k_{i}\right)\right|
\end{aligned}
$$

Table 5 shows the results of Joint Wright multiple variance ratio test.

The test results show that under the heteroscedasticity, $J R_{2}$ in $r_{1}$ before the adjustment is not statistically significant, but after the adjustment, the value is statistically significant, which rejects the original hypothesis and proves not following the martingale process; while regardless of being unadjusted or adjusted, the statistics of $r_{2}$ are basically not significant, which is to accept the original hypothesis and following the martingale process is proved. The value of $r_{3}$, not

Table 4. Results of chow denning multiple variance ratio test.

\begin{tabular}{ccccc}
\hline \multirow{2}{*}{ Return } & \multicolumn{2}{c}{ Unadjusted } & \multicolumn{2}{c}{ Adjusted } \\
\cline { 2 - 5 } & $C D_{1}$ & $C D_{2}$ & $C D_{1}$ & $C D_{2}$ \\
\hline$r_{1}$ & $3.7721^{\star * *}$ & 1.4101 & $2.3784^{\star}$ & 1.2819 \\
$r_{2}$ & 1.9258 & 1.0292 & 2.0214 & 1.0790 \\
$r_{3}$ & $2.3801^{*}$ & 1.2831 & $2.3784^{\star}$ & 1.2819 \\
\hline
\end{tabular}

Note: $C D_{1}$ is the statistic under homoscedasticity and $C D_{2}$ is the statistic under heteroscedasticity. Through simulation, the critical values are respectively $3.09,2.57$ and 2.31 under significant levels of $1 \%, 5 \%$ and $10 \% .{ }^{* *},{ }^{* *}$ and ${ }^{*}$ respectively shows the significance under significant levels of $1 \%, 5 \%$ and $10 \%$.

Table 5. Results of joint wright multiple variance ratio test.

\begin{tabular}{ccccccc}
\hline \multirow{2}{*}{ Return } & \multicolumn{3}{c}{ Unadjusted } & \multicolumn{3}{c}{ Adjusted } \\
\cline { 2 - 7 } & $J R_{1}$ & $J R_{2}$ & $J S_{1}$ & $J R_{1}$ & $J R_{2}$ & $J S_{1}$ \\
\hline$r_{1}$ & $3.0588^{* *}$ & 1.5093 & $22.3752^{\star * *}$ & 2.0801 & $2.4272^{* *}$ & $54.6185^{* * *}$ \\
$r_{2}$ & 1.3624 & 1.4781 & 1.7335 & 1.4346 & 1.5741 & $106.1170^{\star * *}$ \\
$r_{3}$ & 2.0731 & $2.4213^{* *}$ & 1.7464 & 2.0801 & $2.4272^{\star *}$ & $54.6185^{* * *}$ \\
\hline
\end{tabular}

Note: The critical values of the Joint Wright test are shown in attached table two. ${ }^{* * *}$ and ${ }^{* *}$ respectively shows the significance under significant levels of $1 \%$ and $5 \%$. 
statistically significant before the adjustment, is significant after the adjustment, therefore, we believe the martingale process is not followed.

\subsection{Comparison of Results from the Four Tests}

Comparison of the results above can be summarized as Table 6. Compared with other tests, Joint Wright multiple variance ratio test is more reliable, and the adjusted data are more effective than the unadjusted counterparts.

Table 6 shows: Before the adjustment, among the four tests namely Lo MacKinlay traditional variance ratio test, Wright non-parametric variance ratio test, Chow Denning multiple variance ratio test and Joint Wright multiple variance ratio test, the Wright test fails to while all the other three tests follow a martingale process.

After the adjustment, $r_{1}$ in the Wright test fails to follow a martingale process while in the Joint Wright test, $r_{1}$ and $r_{3}$ both fail to follow a martingale process.

Given that the Joint Wright multiple variance ratio test corrects the two defects of traditional variance ratio test at the same time, overcoming the problem of scale distortion among small-size samples as well as solving the problem of selecting $k$, we choose the adjusted results of Joint Wright test: the market in stage $r_{1}, r_{3}$ fails to be weak-form efficient while the market in stage $r_{2}$ achieves weak-form efficiency.

\section{Conclusions and Analysis}

According to the tests above, we draw the following conclusions:

The first stage does not follow the martingale process and the EU ETS spot market is non-efficient. For a fledgling market, its market mechanism was not yet perfect. Due to a lack of experience and historical information to draw on, a large amount of irrational investors showed up in the market, leading to severe information asymmetry and high trading costs. As a result, there was a large amount of "noise" in prices, which could not correctly demonstrate information of the market. Therefore, the market in this stage fails to be weak-form efficient.

The second stage follows the martingale process and the EU ETS spot market is weak-form efficient. Compared with being in the first stage, the carbon trading market in the second one showed the following features: first, the carbon trading

Table 6. Comparison of results of variance ratio test.

\begin{tabular}{ccccccccc}
\hline & \multicolumn{4}{c}{ Unadjusted } & \multicolumn{4}{c}{ Adjusted } \\
\hline & $\begin{array}{c}\text { Lo } \\
\text { MacKinlay }\end{array}$ & Wright & $\begin{array}{c}\text { Chow } \\
\text { Denning }\end{array}$ & $\begin{array}{c}\text { Joint } \\
\text { Wright }\end{array}$ & $\begin{array}{c}\text { Lo } \\
\text { MacKinlay }\end{array}$ & Wright & $\begin{array}{c}\text { Chow } \\
\text { Denning }\end{array}$ & $\begin{array}{c}\text { Joint } \\
\text { Wright }\end{array}$ \\
\hline$r_{1}$ & A & R & A & A & A & R & A & R \\
$r_{2}$ & A & A & A & A & A & A & A & A \\
$r_{3}$ & A & A & A & A & A & A & A & R \\
\hline
\end{tabular}

Note: A means to accept the original hypothesis, $\mathrm{R}$ means to reject the original hypothesis. 
market reached a certain scale as the trading volume was gradually enlarged and the liquidity was greatly enhanced; second, policies were gradually stabilized, the mechanism was formed and with constant improvement, and the streamlined and standardized system greatly reduced the trading cost; third, enterprise participation was greatly improved, participants' mastering degree of the trading mechanism was deepened, and the investment idea was taking shape initially. Therefore, market in this stage has shown its weak-form efficiency and the price is more reasonable.

The third stage fails to follow the martingale process and the EU ETS spot market is non-efficient. In the third stage, international climate negotiations encountered withdrawal of western countries like the United States, thus greatly dampened the enthusiasm of the carbon market participants. As a result, the market trading shrunk, the liquidity was reduced and the market prices were hovering at the low point. Undoubtedly, there is a certain relationship between the test results on this market and the length of time of samples. The relatively short time since the start of the third stage has caused an unsatisfactory testing effect. Therefore, the effectiveness of this stage may need a longer time for test.

\section{Acknowledgements}

This paper is a staged achievement of the major project of National Social Science Fund of China (15AGJ009). The authors appreciate the financial support of National Social Science Fund and the suggestions from the anonymous jury. The authors are responsible for the consequences of this article.

\section{References}

[1] Fama, E.F. (1965) The Behavior of Stock-Market Prices. Journal of Business, 38, 34-105. https://doi.org/10.1086/294743

[2] Charles, A., Darné, O. and Fouilloux, J. (2013) Market Efficiency in the European Carbon Markets. Energy Policy, 60, 785-792.

https://doi.org/10.1016/j.enpol.2013.05.036

[3] Daskalakis, G. (2013) On the Efficiency of the European Carbon Market: New Evidence from Phase II. Energy Policy, 54, 369-375. https://doi.org/10.1016/j.enpol.2012.11.055

[4] Joyeux, R. and Milunovich, G. (2010) Testing Market Efficiency in the EU Carbon Futures Market. Applied Financial Economics, 20, 803-809. https://doi.org/10.1080/09603101003636220

[5] Montagnoli, A. and Vries, F.P.D. (2010) Carbon Trading Thickness and Market Efficiency. Energy Economics, 32, 1331-1336. https://doi.org/10.1016/j.eneco.2010.04.001

[6] Daskalakis, G. and Markellos, R.N. (2008) Are the European Carbon Markets Efficient? Social Science Electronic Publishing, Rochester, 17.

[7] Deeney, P., Cummins, M., Dowling, M. and Smeaton, A.F. (2016) Influences from the European Parliament on EU Emissions Prices. Energy Policy, 88, 561-572. https://doi.org/10.1016/j.enpol.2015.06.026

[8] Perthuis, C.D. and Trotignon, R. (2014) Governance of Co 2, Markets: Lessons from 
the EU Ets. Energy Policy, 75, 100-106. https://doi.org/10.1016/j.enpol.2014.05.033

[9] Kim, J.H. and Shamsuddin, A. (2008) Are Asian Stock Markets Efficient? Evidence from New Multiple Variance Ratio Tests. Journal of Empirical Finance, 15, 518-532. https://doi.org/10.1016/j.jempfin.2007.07.001

[10] Lo, A.W. and MacKinlay, A.C. (1988) Stock Market Prices Do Not Follow Random Walks: Evidence from a Simple Specification Test. The Review of Financial Studies, 1, 41-66. https://doi.org/10.1093/rfs/1.1.41

[11] Wright, J. (2000) Alternative Variance-Ratio Tests Using Ranks and Signs. Journal of Business \& Economic Statistics, 18, 1-9.

[12] Chow, K.V. and Denning, K.C. (1993) A Simple Multiple Variance Ratio Test. Journal of Econometrics, 58, 385-401.

https://doi.org/10.1016/0304-4076(93)90051-6 